\title{
Influência do armazenamento e prazo de validade na estabilidade e ocorrências de eventos adversos no uso de medicamentos
}

\author{
Influence of storage and expiry date on stability and occurrences of adverse events in the use of \\ medicines
}

Influencia del almacenamiento y fecha de caducidad en la estabilidad y ocurrencia de eventos adversos en el uso de medicamentos

\section{Resumo}

O consumo de medicamentos impróprios pode ser importante na ocorrência de eventos adversos e gerar prejuízos a saúde dos pacientes. São percebidos que fatores internos e externos, físicos e químicos, possuem capacidade de influenciar na estabilidade dos constituintes e podem mudar a natureza dos desfechos clínicos mediante utilização destes medicamentos. Este trabalho tem por objetivo levantar na literatura sobre as modificações na constituição dos fármacos ao longo do prazo de validade. Trata-se de uma revisão de literatura onde foram realizadas buscas de artigos científicos em bancos eletrônicos da SciELO, LILACS e MEDLINE com palavras chaves concordantes com o DECs. O prazo de validade dos medicamentos é determinado mediante avaliações técnicas e obediência a regulamentos sanitários onde é assegurado que o fármaco está adequado para consumo humano. Após esse período ou desrespeitando essas orientações, é possível que ocorram alterações nas suas constituições que podem provocar intoxicações ou levar a intoxicações como da NET e Sindrome e Steven Jhonson. O consumo medicamentos em condições improprias, ou expirados, têm capacidade de potencializar riscos à saúde e podem promover desfechos sequelantes e letais. Por isso são necessárias medidas e vigilância para o controle da qualidade, da validade, das condições de armazenamento e consumo dos medicamentos.

Palavras-chave: Prazo de validade; Medicamentos de alta vigilância; Prazo de uso de medicamentos.

\begin{abstract}
The consumption of inappropriate medications can be important in the occurrence of adverse events and cause harm to patients' health. It is perceived that internal and external factors, physical and chemical, have the ability to influence the stability of the constituents and can change the nature of clinical outcomes through the use of these drugs. This work aims to survey the literature on changes in the constitution of drugs over the period of validity. This is a literature review where searches were performed for scientific articles in SciELO, LILACS and MEDLINE electronic databases with keywords in agreement with the DECs. The shelf life of medicines is determined through technical evaluations and compliance with health regulations where it is ensured that the drug is suitable for human consumption. After this period or disrespecting these guidelines, it is possible that changes occur in their constitutions that can cause intoxication or lead to intoxication such as NET and Syndrome and Steven Jhonson. The consumption of medications in improper conditions, or expired, has the capacity to increase health risks and can promote sequelae and lethal outcomes. Therefore, measures and surveillance are needed to control the quality, validity, storage and consumption conditions of medicines.
\end{abstract}

Keywords: Expiration date; Highly surveillance medicines; Term of use of medicines.

\section{Resumen}

El consumo de medicamentos inapropiados puede ser importante en la ocurrencia de eventos adversos y causar daños a la salud de los pacientes. Se percibe que los factores internos y externos, físicos y químicos, tienen la capacidad de influir en la estabilidad de los constituyentes y pueden cambiar la naturaleza de los resultados clínicos mediante el uso de estos fármacos. Este trabajo tiene como objetivo revisar la literatura sobre los cambios en la constitución de las 
drogas durante el período de validez. Se trata de una revisión de la literatura donde se realizaron búsquedas de artículos científicos en las bases de datos electrónicas SciELO, LILACS y MEDLINE con palabras clave de acuerdo con las DEC. La vida útil de los medicamentos se determina mediante evaluaciones técnicas y el cumplimiento de la normativa sanitaria donde se asegura que el medicamento es apto para el consumo humano. Después de este período o sin respetar estas pautas, es posible que se produzcan cambios en sus constituciones que pueden causar intoxicación o llevar a intoxicación como NET y Síndrome y Steven Jhonson. El consumo de medicamentos en condiciones inadecuadas o vencidas tiene la capacidad de aumentar los riesgos para la salud y puede promover secuelas y resultados letales. Por tanto, se necesitan medidas y vigilancia para controlar la calidad, validez, condiciones de almacenamiento y consumo de los medicamentos.

Palabras clave: Período de validez; Medicamentos de alta vigilancia; Plazo de uso de los medicamentos.

\section{Introdução}

A inovação e o desenvolvimento de fármacos mesmo substanciado por novas tecnologias de modelamento químico, ainda não foi capaz de neutralizar as ocorrências de deterioração temporal, efeitos colaterais e possíveis eventos adversos no consumo de medicamentos (Amaral et al, 2017).

Observando na história de consumo de medicamentos, a lembrança dos danos associados ao uso da talidomida e do etilenoglicol, nos fazem recordar que existem vários fatores com potencial de gerar danos aos organismos (Moro \& Invernizzi, 2017). Na mesma linha, a importância de ações como a evolução da farmacovigilância, a implementação de ensaios clínicos, comitês de ética e de protocolos de controle de qualidade, estabilidade, biodisponibilidade e a determinação do prazo de validade, colaboram para a segurança no uso destes produtos (Mirco et al, 2007).

Dentre as várias características que envolvem o ciclo gerencial e de consumo de medicamentos, um fator importante a ser observado é a possibilidade da utilização destes produtos para além das validades estipuladas pelos fabricantes. O assunto é bastante polêmico e produz discordâncias na comunidade científica, principalmente quando se observa o potencial de danos associados ao consumo deles nestas condições (Barata-Silva et al, 2017).

Assim, o prazo de validade de um medicamento ganha destaque na discussão, uma vez que esse é o período em que o fabricante garante aestabilidade e eficácia do fármaco (Facci et al, 2020). Essa condição depende de vários fatores que podem ser internos ou externos a molécula, e a perda desta condição pode repercutir ao invés de benefícios, em efeitos prejudiciais ao paciente (Souza, 2014).

O controle de qualidade aplicado aos processos de fabricação, possuem como objetivo geral, assegurar que existe segurança a eficácia no uso destes medicamentos por todo esse período em que ele é oferecido ao consumo. Somente após a expiração do prazo, é que os medicamentos passarão a sofrer alterações na natureza de sua constituição, ou na capacidade de produção de efeito (Pirani et al, 2020).

Assim a percepção de ocorrências sobre as alterações organolépticas que estão relacionadas ao polimorfismo dos fármacos e por reações químicas que estão relacionadas com as reações de decomposição dos fármacos, não deveriam ser observadas nestes períodos.

Com base nessas informações, este estudo tem por objetivos levantar como são constatadas as modificações na constituição dos fármacos que podem ocorrer na medida que a se aproxima ou se ultrapassa o período de validade. Destacando os fatores físicos e químicos, internos e externos que são apresentados com potencial de interferem na estabilidade dos fármacos ao longo do prazo de validade determinado pelo fabricante.

Ademais, propõe-se analisar como a literatura científica apresenta a capacidade dos processos de controle de qualidade preverem as alterações nos medicamentos a partir da fabricação e analisar os possíveis eventos adversos associados a desvios de qualidade da medicação e as datas de validade. 


\section{Metodologia}

Este trabalho trata-se um uma revisão de literatura integrativa com base em SOUSA (2010) e colaboradores, onde foram levantadas informações sobre as consequências do consumo de medicamentos após o seu prazo de validade através de trabalhos científicos já publicados sobre o tema, para a realização realização desta revisão utilizou-se como base literária artigos científicos selecionados nas bases de dados eletrônicas de busca Scientic Eletronic Library Online (SciELO), Literatura Latino-Americano e do Caribe em Ciências da Saúde (LILACS) e Medical Literature Analysis And Retrieval System Online (MEDLINE).

Para sustentar a busca pelos artigos, foram utilizados palavras chaves e descritores prazo de validade, medicamentos vencidos, medicamentos de alta vigilância, Necrólise Epidérmica Tóxica e prazo de uso de medicamentos checados junto ao DECs (Descritores em Ciências da Saúde) garantindo assim a utilização de termos relevantes para as referidas buscas.

As pesquisas foram conduzidas pelos autores de forma independente nos bancos de dados propostos, sendo que para maximizar e refinar a seleção, foi aplicado o cruzamento dos descritores entre si com auxílio do termo booleano "e/AND" e suas combinações utilizadas em português e inglês, favorecendo assim uma seleção refinada de artigos.

Inicialmente os artigos foram selecionados a partir da leitura título em português ou inglês e que revelaram haver clara ligação com o tema deste trabalho. Estes artigos incialmente selecionados foram reclassificados obedecendo aos critérios de inclusão, de ter resumo disponível em português ou inglês, estar disponível na íntegra para leitura, ter sido publicado entre 2010 e 2021, possuir clara indicação de autoria, ter sido publicados em periódicos indexados nos referidos bancos de dados.

Foram considerados critérios de exclusão, não estar disponível na integra para leitura, terem sido fora do período de 2010 e 2021, ou que após a leitura não estavam relacionados ao tema deste trabalho. As informações extraídas dos estudos selecionados, foram realizadas de forma descritiva e qualitativa, possibilitando assim, observar, contar descrever, classificar os resultados e argumentar sobre o tema explorado nessa revisão. O caminho metodológico percorrido para escolha dos artigos, pode ser visualizado no Quadro 1.

Quadro 1. Etapas da seleção dos artigos científicos utilizados neste trabalho.

\begin{tabular}{|c|c|c|}
\hline ETAPA & DESCRIÇÃO DA ETAPA & RESULTADO \\
\hline 1 & $\begin{array}{l}\text { Seleção das palavras chaves e termos } \\
\text { descritores. }\end{array}$ & $\begin{array}{c}\text { prazo de validade, medicamentos } \\
\text { vencidos, medicamentos de alta } \\
\text { vigilância, Necrólise Epidérmica } \\
\text { Tóxica e prazo de uso de } \\
\text { medicamentos }\end{array}$ \\
\hline 2 & $\begin{array}{l}\text { Pesquisa utilizando isoladamente os } \\
\text { descritores em português e inglês. }\end{array}$ & 135 artigos \\
\hline 3 & $\begin{array}{l}\text { Pesquisas utilizando o cruzamento dos } \\
\text { descritores entre si com auxílio do } \\
\text { termo booleano "e/AND” e suas } \\
\text { combinações em português e inglês. }\end{array}$ & 62 artigos encontrado \\
\hline 5 & $\begin{array}{c}\text { Artigos selecionados a partir da leitura } \\
\text { título em português ou inglês com } \\
\text { clara ligação com o tema deste } \\
\text { trabalho. }\end{array}$ & $\begin{array}{c}\text { Artigos selecionados: } 42 \text { Artigos } \\
\text { excluídos: } 08\end{array}$ \\
\hline 6 & $\begin{array}{l}\text { Reclassificação dos artigos utilizando } \\
\text { os termos de inclusão e exclusão. }\end{array}$ & $\begin{array}{l}\text { Artigos selecionados: } 34 \\
\text { Artigos excluídos: } 12\end{array}$ \\
\hline 7 & $\begin{array}{l}\text { Artigos selecionados para sustentação } \\
\text { dos resultados e argumentação deste } \\
\text { trabalho. }\end{array}$ & 22 artigos \\
\hline
\end{tabular}

Fonte: Autores. 


\section{Resultados e Discussão}

O desenvolvimento de fármacos, está intimamente ligado as ações de controle de qualidade no processo de produção, a fim de garantir a segurança de seu consumo e a eficácia que se espera do mesmo. Ainda no processo de fabricação, são realizados testes, a fim de definir o seu prazo de validade, que é o período em que o fabricante garante a sua estabilidade (Barata-Silva et al, 2017).

Os acidentes relatados com novos medicamentos durante a década de 50, podendo ser destacado o caso da talidomida, fizeram com que se investisse em estratégias de farmacovigilância, a fim de prevenir a ocorrência de efeitos adversos ou outros problemas relacionados ao consumo de medicamentos (Mirco et al, 2007; Moro et al, 2017).

Umas das ações a serem adotadas em prol da segurança no consumo foi justamente que os medicamentos passaram a ter um prazo de validade pré-determinado, sendo que o uso dessas substâncias após esse período, pode trazer danos até irreversíveis à saúde dos usuários (Mirco et al, 2007).

A garantia da estabilidade do fármaco é promovida através do controle de qualidade, que com as técnicas analíticas, como os métodos cromatográficos e espectrofotométricos visam garantir que o medicamento seja seguro, eficaz e estável para consumo, além de determinar por quanto tempo é propício ao uso (Facci et al, 2020).

A estabilidade de um medicamento pode ser prejudicada por diversos fatores intrínsecos ou extrínsecos, e estes podem interferir diretamente na segurançae eficácia dos medicamentos, estudos sobre o tempo de vida últil de um medicamento após sua data de vencimento, relatam que muitos poderiam ter sua vida últil extendida se armazenado de forma adequada (De Oliveira et al, 2020; Lyon et al, 2006).

Dentre os fatores extrínsecos, ditos também como ambientais, cita-se a temperatura que apresenta uma relação direta de risco com sua elevação e pode repercutir na degradação direta da molécula. Outro fator é a luz que pode induzir degradações por meio de reações químicas ou físicas indesejadas, os grupos puncionais dos fármacos contribuem para a ocorrência dessas reações. A exposição à lux, pode levar a oxidação da molécula, reação favorecida em substâncias que contenham em sua fórmula o catecol, como por exemplo a epinefrina e a norepinefrina, essa reação química leva a uma descoloração da substância devido à formação de partículas de polimerização e de adrenocromo (Ahmad et al, 2016; Zilker et al, 2019). A umidade afeta a integridade e estabilidade física da substância repercutindo diretamente na quantidade de tempo de armazenamento (Gil, 2010; Pinto et al, 2016).

Já os fatores intrínsecos, estão associados intimamente ao fármaco e o que ocorre através de reações químicas de decomposição, como as reações de hidrólise favorecidas por exemplo por lactamas e ésteres, além de amidas e carbamatos, os anestésicos locais, como a lidocaína e bupivacaína sofrem essas reações se tornando menos estáveis e inviáveis para uso após ter o seu prazo de validade expirado. O ácido acetilsalicílico também sofre reação de hidrólise, o que causa a perda da sua porção acetílica (Zilker et al, 2019). Reações de oxidação que ocorrem com ganho de uma molécula de oxigênio ou a perda de um hidrogênio, a fotólise onde a presença da luz pode ocasionar na lise da molécula e a racemização onde a mistura de dois enântiomeros pode causar efeitos indesejáveis ou ainda a perda da atividade do fármaco (Meirelles, 2014; De Araújo Silva, et al, 2020). Ainda sobre a estabilidade dos fármacos, algumas alterações podem ser evidenciadas facilmente, como por exemplo alterações de odor, sabor ou coloração (Martins et al, 2018).

Alguns medicamentos são importantes por terem um alto índice de consumo, e os potenciais danos produzidos se utilizados de forma adulterada, devem ser levados em consideração. Por exemplo a tetraciclina, um antibiótico macrolídio, que se utilizado na forma alterada, como pode acontecer, após o seu vencimento, pode provocar acidose tubular renal que é uma patologia decorrente de defeitos na reabsorção de bicarbonato ou na excreção de hidrogênio (Menegussi et al, 2018). 
Percebe-se ASSIM que através da reação de decomposição, a epimerização, a tetraciclina tornou-se um composto tóxico (Zilker et al, 2019).

Um dos fatores que contribuem para a utilização de medicamentos vencidos, é a falta de recursos financeiros, o que faz com que um fármaco mesmo com seu prazo de validade expirado, seja utilizado. Em estudo realizado por Iserson (2021), relata-se que o uso de medicamentos vencidos, é arriscado e que ainda são poucos os estudos sobre os riscos e os danos associados a esta prática, porém levando em consideração casos extremos, como em caso de vida ou morte e falta de opções, com o consentimento dos paciente ou familiares, possibilidades desta natureza podem ser também consideradas a bem de preservar a vida do paciente (Inserson, 2021).

De maneira geral, o acesso aos medicamentos tem sido facilitado ao longo dos anos, inclusive com investimentos bilionários, a fim de que os pacientes tenham opções e acesso a tratamentos farmacológicos eficientes e oportunos para a melhora das enfermidades. Todavia, mesmo com estes investimentos, é possível notar que tanto na dispensação quanto no tratamento ainda podem ocorrer equívocos de uso, e eventualmente o paciente pode não concluir o tratamento farmacológico, produzindo sobras de medicamentos em residências. $\mathrm{O}$ uso destes medicamentos que tendem a expirar seus prazos de validade, podem também contribuir para a falta de efetividade, ou induzir intoxicações, efeitos colaterais ou ainda desencadear eventos adversos (Fernandes et al, 2020).

As reações adversas causadas por medicamentos, podem resultar em danos e sequelas ao estado de saúde do paciente ou ainda serem fatais. A condição de não serem percebidas quando ocorrem e inclusive serem correlacionadas a outras doenças, podem resultar em situações de não serem tratadas corretamente ou ainda, o paciente continuar consumindo o medicamento que está provocando este malefício a sua vida. O conhecimento sobre as reações adversas é essencial para a contribuição do bem-estar do paciente, a farmacovigilância tem papel fundamental na orientação sobre o possível surgimento dessas reações (Randhawa et al, 2017).

A NET- Necrólise Epidérmica Tóxica é uma síndrome em sua grande maioria causada por uma reação adversa à medicamentos que tem início com sintomas de febre e tosse e se agrava causando lesões na pele e mucosas, chamada farmacodermia. Ainda que na literatura não tenham relatos, fármacos ingeridos fora do seu prazo de validade podem facilitar ou serem promotores deste agravo, já que a mesma provém de reações alérgicas entre a droga e seu receptor e ainda de problemas com o seu metabolismo (Kinoshita, 2016; Zhang et al, 2021).

A síndrome de Steven Jhonsons apresenta sintomas semelhantes a necrólise epidérmica tóxica, sendo considerada a forma aguda dela, causando lesões mais leves na pele e atingindo uma porcentagem menor do corpo. A resposta imune que ocorre de forma mais agressiva nessas síndromes, tem relação com os metabólitos originados por estes fármacos, o que pode ocorrer quando com o consumo de medicamentos com prazo de validade expirados e que consequentemente, estrem com estabilidade alterada, podendo produzir metabólitos tóxicos (Lonjou et al, 2008; Mccullough et al, 2017).

Os fármacos mais citados com relação a NET e a síndrome de Steven Jhonsons são carbamazepina, fenobarbital, sulfonamidas, alopurinol e fenitoína e as reações químicas podem estar diretamente relacionadas com o processo envolvido no desenvolvimento da síndrome, uma vez que essas reações provocam alterações estruturais no fármaco (Silva et al, 2017; Neto et al, 2019; Zhang et al, 2021). As sulfonamidas por exemplo tem a sua hidrolise favorecida, e apresenta propriedades químicas e físicas variadas por apresentar uma variação nos seus grupos R, o que pode motivar o processo alérgico no organismo (Oliveira, 2005).

A quiralidade tem grande importância quanto ao efeito dos fármacos, podendo o mesmo composto ser apresentado em duas formas, chamadas de enantiômeros ou diastereoisômeros podendo ou não possuir a mesma imagem especular, e ainda cada forma ter um diferente efeito farmacológico (Orlando et al, 2007). 
Após o período proposto de validade de um fármaco, as reações depreciativas da qualidade e estabilidade podem ser aceleradas e passar a prevalecer a forma tóxica do composto, repercutindo em danos à saúde, por vezes até irreversíveis, pois ao ter sua estrutura modificada, a interação fármaco-receptor é comprometida, interferindo na farmacocinética e no mecanismo de ação inicialmente proposto (Orlando et al, 2007).

Algumas drogas possuem características que podem contribuir para reações de decomposição podendo após de vencidas ser mais agressivas ao organismo, como por exemplo as lactomas, lactanas, ésteres e amidas que tem a hidrólise favorecida.

Ao realizar testes de pureza em laboratórios de controle de qualidade, podemos notar que após o vencimento os medicamentos se tornam inviáveis para consumo; em um teste de coloração de sulfato de salbutamol após seu prazo de validade, nota-se uma coloração escura, demostrando que o fármaco se tornou instável (Klaassen et al, 2009).

A utilização de antibióticos fora do prazo de validade, podem repercutir em desenvolvimento da resistência bacteriana, além do fármaco perder em eficiência e comprometendo o sucesso do tratamento. (De Oliveira et al, 2021)

Fármacos líquidos, se armazenados de forma inadequada e por muito tempo, podem ser contaminados por cepas bacterianas, prejudicar o organismo que vier a consumi-lo (Klaassen et al, 2009)

Os prazos de utilização dos medicamentos devem ser utilizados e armazenados conforme descreve as orientações dos fabricantes e dos profissionais de saúde, em especial o farmacêutico. Pois é dessa maneira que se consegue elevar a segurança no uso e diminuir a probabilidade de ocorrências de eventos adversos provocados através de seu consumo.

De maneira geral, é fato que esse assunto ainda reserva questionamentos, pois existem poucas evidências sobre as consequências provocadas pelo consumo de produtos inseguros e alterados, bem como dos danos provocados por consequência destes tratamentos.

\section{Considerações Finais}

O consumo medicamentos em condições improprias, ou expirados, têm capacidade de potencializar riscos à saúde e podem promover desfechos sequelantes e letais. Por isso são necessárias medidas e vigilância para o controle da qualidade, da validade, das condições de armazenamento e consumo dos medicamentos.

$\mathrm{O}$ entendimento sobre os efeitos dos medicamentos nos organismos e suas modificações, interações e incompatibilidades são dinâmicas e complexas, ainda mais quando se considera o fator tempo e as intempéries do armazenamento. Nessa linha, os estudos sobre os efeitos colaterais e eventos adversos necessitam ser estimulados e realizados, para se complementarem com as análises dos programas de controle da qualidade de medicamentos. E assim com os conhecimentos interdisciplinares dos profissionais de saúde, resultem na garantia e elevação nos níveis de segurança na utilização de medicamentos.

\section{Referências}

Ahmad, S., Ahmed, Z., Anwar, M. A. \& Sheraz, M. S. (2016). Photostability and photostabilization of drugs and drug products, Int. J. Photoenergy 1-19

Amaral, A. T. D., Andrade, C. H., Kümmerle, A. E., \& Guido, R. V. (2017). A evolução da Química Medicinal no Brasil: Avanços nos 40 anos da Sociedade Brasileira de Química. Química Nova, 40, 694-700.

Barata-Silva, C., Hauser-Davis, R. A., Silva, A. L. O. D., \& Moreira, J. C. (2017). Desafios ao controle da qualidade de medicamentos no Brasil. Cadernos Saúde Coletiva, 25, 362-370.

Brade, W. P., Herdrich, K., Kachel-Fischer, U. \& Araújo, C. E. (1991). Dosing and side-effects of ifosfamide plus mesna. Journal of Cancer Research and Clinical Oncology, 117(S4), S164-S186. doi:10.1007/bf01613224 
Research, Society and Development, v. 10, n. 15, e91101522341, 2021

de Oliveira, J. P. B., Gonzalez, B. L., Chierrito, D., Teston, A. P. M., de Mello, J. C. P., Romanichen, F. M. D. F., \& de Medeiros Araújo, D. C. (2020). Análise do peso médio, resistência mecânica e desintegração de comprimidos genéricos de varfarina sódica. Brazilian Journal of Development, 6(9), 6986569875 .

de Araujo Silva, J. G., Neto, J. G. P., \& de Araujo Freire, R. (2020). Correlação entre estabilidade e condições de armazenamento de medicamentos no interior das ambulâncias do Serviço Móvel de Urgência (SAMU). Brazilian Journal of Development, 6(12), 94622-94632.

de Oliveira, R. X., Silva, C. H., do Carmo Cupertino, M., da Silva, E. F., da Silva, M. C., Miguel, P. S. B., \& Moreira, T. R. (2021). O uso de antimicrobianos na Atenção Primária à Saúde. Brazilian Journal of Health Review, 4(1), 3048-3056.

Facci, J., Diniz, L. F., Reis, N. F., \& Fernandes, C. (2020). Evolução da legislação e das técnicas analíticas aplicadas a estudos de estudos de estabilidades de insumos e produtos farmacêuticos. Química Nova, 43, 959-73

Gil, E. D. S. (2010). Controle físico-químico de qualidade de medicamentos. In Controle físico-químico de qualidade de medicamentos (pp. 511-511).

Iserson, K. V. (2021). Should We Use Expired Drugs When Necessary? The Journal of Emergency Medicine, 60(5), 669-73. doi:10.1016/j.jemermed.2021.02.002

Klaassen, C. D., \& Watkins III, J. B. (2009). Fundamentos em Toxicologia de Casarett e Doull (Lange). AMGH Editora.

Martins, M. A. F., \& Galato, D. (2018). Irregularidades dos medicamentos comercializados no Brasil: uma análise das notificações e das medidas sanitárias de 2012 a 2017. Vigilância Sanitária em Debate: Sociedade, Ciência \& Tecnologia (Health Surveillance under Debate: Society, Science \& Technology)-Visa em Debate, 6(4), 23-33.

Souza, J. N. D. (2014). Estudo de estabilidade: fatores que influenciam na estabilidade do medicamento.

McCullough, M., Burg, M., Lin, E., Peng, D., \& Garner, W. (2017). Steven Johnson Syndrome and Toxic Epidermal Necrolysis in a burn unit: A 15-year experience. Burns, 43(1), 200-205.

Moro A.; Invernizzi, N. (2017). A tragédia da talidomida: a luta pelos direitos das vítimas e por melhor regulação de medicamentos. História, Ciências, SaúdeManguinhos. 24(3). https://doi.org/10.1590/S0104-59702017000300004.

Neto, H. C., Chagas, B. F., Soares, M. Z., Lachinski, R. E., \& Linartevichi, V. F. (2019). Síndrome de Stevens-Johnson associada a fenitoína em pósoperatório de hemorragia intraparenquimatosa cerebral: relato de caso. Fag Journal Of Health (FJH), 1(4), $169-184$.

Olson K. R., Anderson I. B., Rodrigues D. C., \& Benowitz N. L. et al. (2014). Manual de toxicologia clínica. AMGH Editora.

Pereira, G. C., Barbosa, N. A., de Souza, V. O., de Lima, R. Q., \& da Silva, M. T. (2020). Avaliação da qualidade dos comprimidos de ibuprofeno vendidos irregularmente no centro de Manaus em comparação aos medicamentos comercializados em drogarias. Brazilian Journal of Technology, 3(4), 160-168.

Pinto, V. B. (2016). Armazenamento e distribuição: o medicamento também merece cuidados. Uso Racional de Medicamentos: fundamentação em condutas terapêuticas e nos macroprocessos da Assistência Farmacêutica, 1(12), 1-7.

Randhawa G. K., Sharma R., Singh N. R., \& Sharma N. (2017). A Qualitative and Quantitative Comparison of Adverse Drug Reaction Data in Different Drug Information Sources. Int J Appl Basic Med Res.; (4): 223-22710.4103/ijabmr.IJABMR_18_17.

Souza, M. T. de, Silva, M. Dias da \& Carvalho, R Integrative review: what is it? How to do it?. Einstein (São Paulo) 8, (1)102-106. <https://doi.org/10.1590/S1679-45082010RW1134>. https://doi.org/10.1590/S1679-45082010RW1134.

Stark G. J. P., Fawcett I. G., \& Tucker. (1997). A study of the stability of some commercial solid dosage forms beyond their expiration dates, Pharm. J. 258. $637-640$.

Zhang, J., Lei, Z., Xu, C., Zhao, J., \& Kang, X. (2021). Current Perspectives on Severe Drug Eruption. Clinical Reviews in Allergy \& Immunology, 1-17.

Zilker M., Sorgel F., \& Holzgrabe U. (2019). A systematic review of the stability of finished pharmaceutical products and drug substances beyond their labeled expiry dates. Journal of Pharmaceutical and Biomedical Analysis. 10.1016/j.jpba.2019.01.016 